\title{
Research on the Microscopic Mechanism of the Bond Breakage of Cemented Carbide Tools
}

\author{
Jinguo Chen ${ }^{1,2}$ - Minli Zheng ${ }^{1},{ }^{*}$ - Yushuang Sun ${ }^{1}$ - Wei Zhang ${ }^{1}$ - Pengfei Li $^{1}$ \\ ${ }^{1}$ Harbin University of Science and Technology, College of Mechanical and Power Engineering, China \\ 2 Putian University, School of Electrical and Mechanical Engineering, China
}

\begin{abstract}
The bond breakage on the rake face of cemented carbide tools has a significant impact on the life of the tool. Using the finite element method, a three-dimensional microstructure model is established for the bond breakage of cemented carbide tools and, based on the analysis of the force conditions in the bond zone, the crack propagation path is investigated at the microscopic scale by varying the cohesive strength of the cemented carbide and the angle between the crack and the rake face to determine the bond breakage process of the cemented carbide tool rake face. The results show that in the absence of the initial cracks, the cracks tend to propagate along the vertical load direction and are deflected due to the increase in the local bonding strength. The angle and location of the cracks and the rake face have a significant influence on the crack propagation path. The stronger the combined force of the cemented carbide, the greater the tensile strength of the material is when there are no cracks in the cemented carbide. In contrast, when initial cracks are present, the crack propagation and crack pinning increase the tensile strength of the material to some extent; however, the increase in the intergranular cracks reduces the overall tensile strength of the material. It is observed from the experiment that intergranular fractures are mainly responsible for the bond breakage of the cemented carbide tools and this result is consistent with the simulation results.
\end{abstract}

Keywords: bond breakage, crack propagation, cemented carbide tool, tensile strength, cohesive zone model, finite element analyses

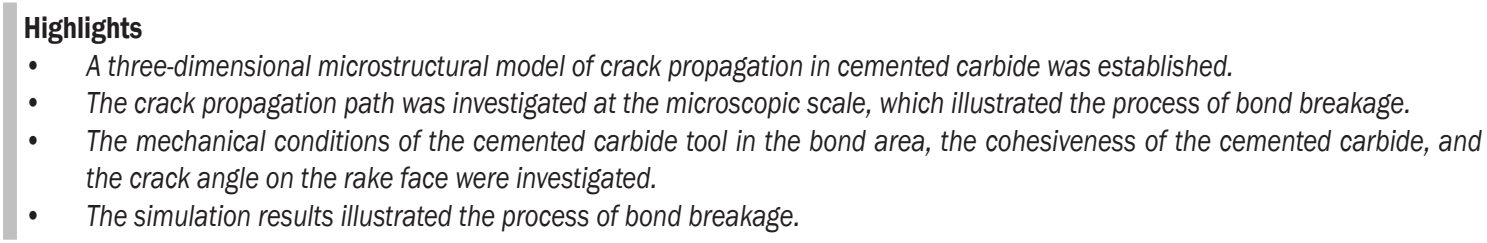

\section{INTRODUCTION}

Many researchers have investigated the behaviour of tool-chip adhesion because the bond breakage of cemented carbide tools is a common occurrence during the process of cutting shell material. Sun et al. [1] studied the bond breakage behaviour of several cemented carbide tools during the cutting of $2.25 \mathrm{Cr}$ 1 Mo steel. It was found that the causes of the tool-chip adhesion were the strong affinity between the tool and the workpiece and the inter-diffusion of the tool and chips under the conditions of high temperature and pressure, which resulted in the formation of a secure joint. Cheng et al. [2] investigated tool bond breakage under extreme overload conditions and the theoretical criterion of tool-chip adhesion was established using experiments and simulations, and a criterion for preventing bond breakage was proposed. Tan et al. [3] researched the distribution of the thermal force of a milling tool with a complex 3D groove and laid a theoretical foundation for analysing the influence of different grooves on the bond breakage mechanisms of milling tools.
The bond breakage process of cemented carbide tools is analysed. During the initial adhesion stage, the surface asperities of the tool and the workpiece in the contact area cause friction. Co in the tool matrix and $\mathrm{Fe}$ in the workpiece belong to the same group of elements, and they have a strong affinity for mutual diffusion. The hardness of the chips is lower than that of the tools, and the asperities of the chips and tool result in bonding in the contact area under high temperature and high pressure, as shown in Fig. 1.

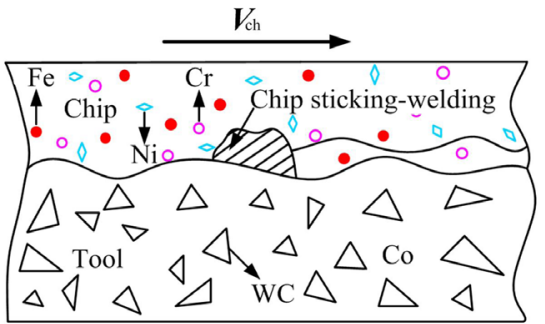

Fig. 1. The initial state of tool-chip adhesion

During the early stages of the cutting process, the type of contact between the tool and chips generally consist of a point contact because of the small contact area; the combined force is relatively small, which 
means that the bonding zone is not stable due to the external force. This results in the exposure of areas with larger hardness on the rake face; therefore, a stable bonding zone cannot be formed at this time. Subsequently, more asperities begin to bond in the adhesion area, and this increase causes the tool-chip contact area to extend from the bonding point to the surface, and the combined force also increases accordingly. When the shear resistance of the diffusion joint in the contact area of the two materials exceeds the shear force produced by the chips passing through the rake face of the tool, the newly formed bonding point is not peeled off, as shown in Fig. 2. As the accumulation continues, a stable tool-chip adhesion phenomenon occurs; this is shown in Fig. 3.

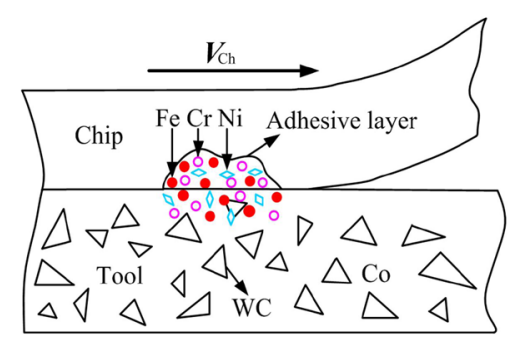

Fig. 2. Stability stage of tool-chip adhesion

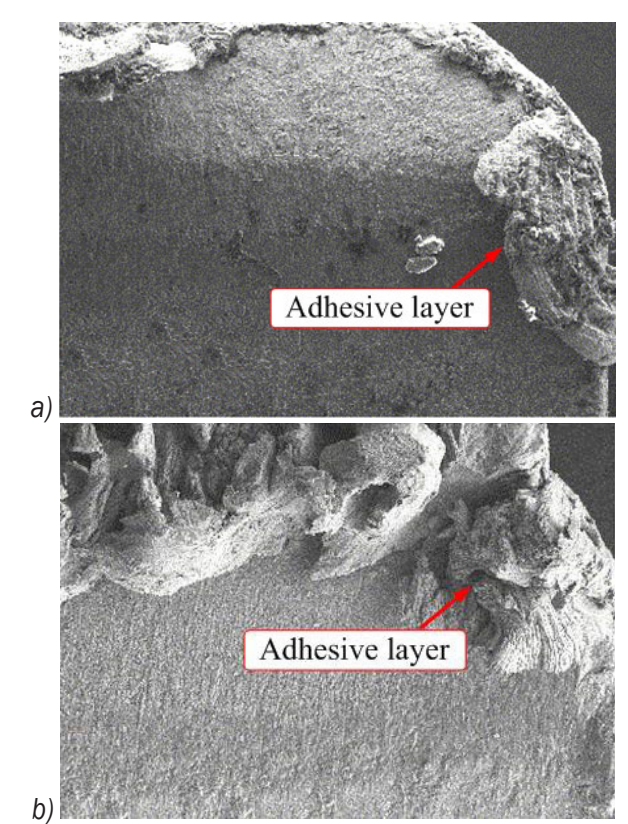

Fig. 3. Microstructural diagram of the tool-chip adhesion on the rake face; a) slight adhesion, and b) severe adhesion

As the cutting continues, due to the continuous element diffusion at the contact area between the tool and chip, extraneous elements such as $\mathrm{Fe}, \mathrm{Cr}$, and other elements enter the tool; in addition, the removed chips contain $\mathrm{W}, \mathrm{Co}$, and other elements. This changes the composition and content of the rake face, and the generation of microcracks under high temperature and high pressure will result in the change in the material strength of the rake face. When the combined force of the chip and the bond area is greater than the internal force of the tool, the material of the rake face will be removed in the form of chips and bond breakage occurs, as shown in Fig. 4.

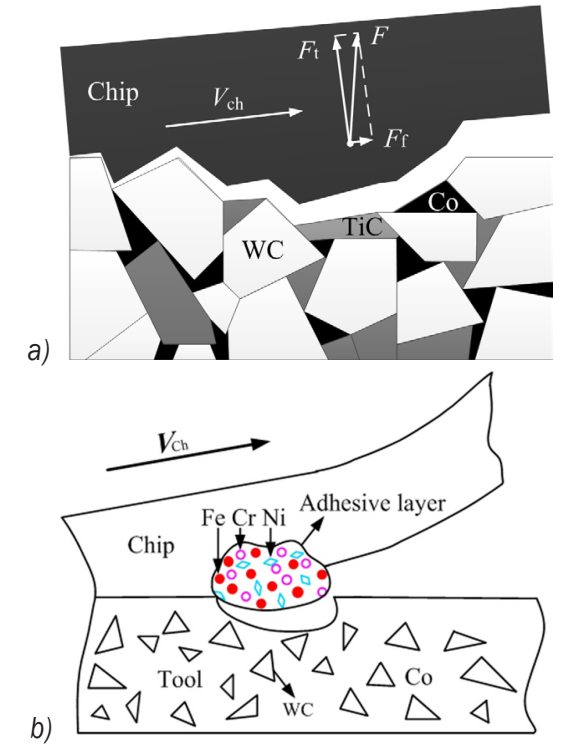

Fig. 4. The adhesion layer is removed in the form of chips; a) forces of the cutting tool in the cutting process, and b) schematic diagram of the formation of tool-chip adhesion

The surface topography of the pits on the cemented carbide tool after bond breakage is observed using a super-depth field emission scanning electron microscope (SEM), as shown in Fig. 5. It is found that the bond breakage has the following characteristics: (1) the area of the bond breakage on the rake face is relatively small. (2) Cracks have formed on the rake face. (3) The surface of the WC particles is intact after the adhesion layer is stripped. These characteristics of the bond breakage and the production of micro defects (such as holes, hot cracks, etc.) on the rake face of the cemented carbide tool occurring during cutting observed at the microscale provide information on the crack propagation path on the rake face of the cemented carbide tool and link the microstructure and macroscopic properties. This information is of great significance to determine the reason for the bond breakage and to improve the service life of the tool.

Many researchers have carried out experimental research on the crack propagation path of cemented carbide tools. Gurland [4] conducted a statistical analysis of the number of WC particles, the WC-WC 
boundary, and the WC-Co boundary in the fracture paths of cemented carbide tools; the results showed that the fractures occurred mostly in the WC particles and at the WC-WC boundary. The Mitsubishi Metals Company in Japan observed the crack propagation paths in a cemented carbide tool during a tensile experiment using a SEM; the researchers found that the cracks all occurred at the boundary of the WC-Co and $\mathrm{WC}-\mathrm{WC}$ and no transgranular fractures occurred. Therefore, the intergranular fracture theory of cemented carbide crack propagation was put forward. The Toshiba Corporation in Japan studied WC-Co fracture morphology, and the fracture behaviour was categorized into three cases: (1) When the grain size of WC was larger than $5 \mu \mathrm{m}$, and the Co content was less than $15 \%$, shearing of the $\mathrm{WC}$ grains occurred. (2) When the grain size of WC was less than $2 \mu \mathrm{m}$, and the Co content was less than $7 \%$, the cracks passed through the WC or WC-Co interface. (3) When the size of the WC particles in the cemented carbide was smaller than $4 \mu \mathrm{m}$ and the Co content was larger than $20 \%$, the crack passed through the Co phase [5]. Sigl and Exner [6] partitioned the crack propagation paths of WC-Co cemented carbide into four categories, including crack propagation through the Co binder phase, along the WC-Co interface, along the WCWC interface, and through WC particles. It was also determined that the path along the WC-Co interface did not occur exactly on the WC-Co interface but in the Co binder phase, which was very close to the WC-Co interface and parallel to the interface area; the expansion path along the WC-Co interface had smaller dimples than the path through the Co binder phase.

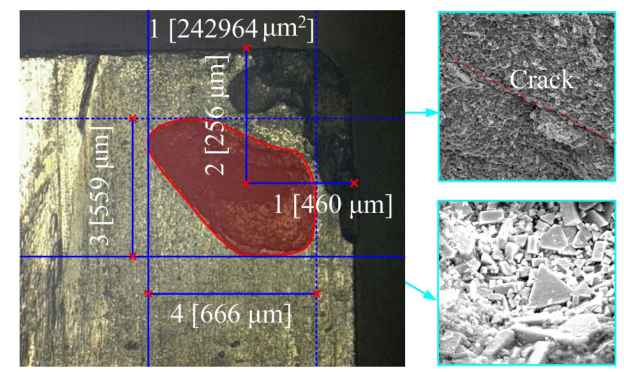

Fig. 5. Bond breakage of the tool

In terms of the research on the cemented carbide simulation: Ljungberg et al. [7] conducted simulations of crack propagation in cemented carbide tools and observed the microstructure using a SEM. The authors established a finite element model and an analysis of the relationship between the maximum plastic zone size of the cemented carbide tip and the mean free path of the cohesive phase and proved that the carbide grain boundaries did not cause changes in the size of the plastic zone. Fischmeister et al. [8] conducted a study on the plastic deformation of the cohesive phase at the crack tip of the cemented carbide tool and analysed the crack propagation behaviour of the cemented carbide by using the finite element simulation method. The results showed that the void nucleation and growth in the area where the $\mathrm{WC}$ phase changed into the Co phase destroyed the reinforcement effect of the plastic zone; the formation and penetration of the void led to crack growth, which resulted in the tear of the perforated plates. Hönle [9] studied the energy consumption and driving force of the crack propagation of cemented carbide using different amounts of Co content and Co inclusions; the results showed that the crack growth occurred at the position of high Co content and Co inclusions with an acute angle. In addition, the influence of the Co inclusion on the energy consumption of the crack propagation was low. Connolly and Mchugh [10] simulated the crack propagation of cemented carbide by using the Gurson model; the results showed that the number of Co layers in the crack propagation path had a large influence on the fracture toughness. Mchugh and Connolly [11] used a numerical simulation to study the ductile failure of the Co binder phase in WC-Co cemented carbide and analysed the crack propagation of cemented carbide under an I-type load. Kim [12] conducted two-dimensional parameterized modelling of cemented carbide; the parameters included the particle size, Co volume fraction, and adjacency. A two-dimensional finite element simulation model of the stress-strain field of the material was developed for predicting the brittle fracture strength of the cemented carbide. Kim et al. [13] used a two-dimensional finite element model to predict the stress-strain distribution and fracture strength of WC-Co composites with a carbide size ranging from $1.4 \mu \mathrm{m}$ to $5.3 \mu \mathrm{m}$ and a carbide volume fraction of 0.7 to 0.9 . Park [14] used a Boolean algorithm to measure the micro parameters of cemented carbide particles in microscopic images, established a microstructure model of carbide-coated tools by using the obtained structural parameters and analysed the cutting life of the coated cemented carbide tools. Sadowski and Nowicki [15] analysed the elastic-plastic response of cemented carbide and studied the effects of particle size and particle number on the material anisotropy using the finite element method; a microstructure simulation of the cemented carbide based on the microstructure observed in the SEM images was conducted. The results showed that the cemented carbide exhibited less anisotropic 
elasticity. Carlsson [16] generated three-dimensional WC grains using the Voronoi method and inserted the Co binder phase between the WC-WC particles to establish a three-dimensional model suitable for modelling the microstructure of the WC-Co cemented carbide; this was used to simulate the yield stress of the material. Park et al. [17] conducted an orthogonal cutting simulation based on the microstructure model of WC-Co cemented carbide to obtain the equivalent stress, strain, and strain energy. A comparison of the predicted and experimental tool failure based on a mixed fracture criterion indicated that the predicted results were in agreement with the experimental results and that the model was suitable for determining the effects of the micro parameters and feed rate on the tool failure. Park et al. [18] established a microstructure prediction model of WC-Co tool failure, validated the results using a turning test, and studied the influence of the microstructure parameters and feed rate on the tool failure using a finite element analysis.

In conclusion, current research on the failure of cemented carbide tools is mainly based on experiments, supplemented by computer simulations. Because of the rigorous experimental conditions, the limitations of the existing experimental equipment, and the high complexity of the research objects, it is difficult to advance the findings. In contrast, the development of computer simulation technology has provided the possibility to explore details at the microscopic level; thus, the breakage caused by the macro-mechanical properties of the tool can be observed at the microscale. This lays the foundation for determining the nature of the bond breakage of the tool. In this study, a three-dimensional microstructure model of the cemented carbide is developed, and the bond breakage of the cemented carbide is simulated in conjunction with the changes in the rake face during the bonding process. The results provide theoretical support for determining the mechanisms of bond breakage.

\section{THREE-DIMENSIONAL MICROSTRUCTURAL MODELING OF CRACK PROPAGATION}

In this study, we establish a microstructure model of the cemented carbide based on the YT5 tool; the main components of the tool are shown in Table 1. Microstructure observations of the YT5 tool during adhesion are conducted using a SEM, and the measurements of the microstructure parameters are obtained. The theory of stereology is used to establish a microstructure model of the cemented carbide.
Stereology is based on the concept that the area ratio of a component in a two-dimensional image is related to the volume ratio of the component in threedimensional space.

Table 1. Main components of the carbide tool YT5

\begin{tabular}{lccc}
\hline components & TiC & WC & Co \\
\hline content [wt $\%]$ & 5 & 85 & 10 \\
\hline
\end{tabular}

\subsection{Determination of Microstructure Parameters}

To establish a three-dimensional microstructure model of the cemented carbide, the TiC particles are considered to have the same material properties as WC particles. Therefore, a corresponding simplification is made here, that is, the $\mathrm{TiC}$ particles are considered as WC particles to study the model crack propagation. Then Image $\mathrm{J}$ software is used to analyse the SEM images of the rake face of the carbide (Fig. 6). The microstructure parameters are calculated to obtain the mean grain size, the volume fraction of each component, and the grain adjacency of the carbide tool rake face.

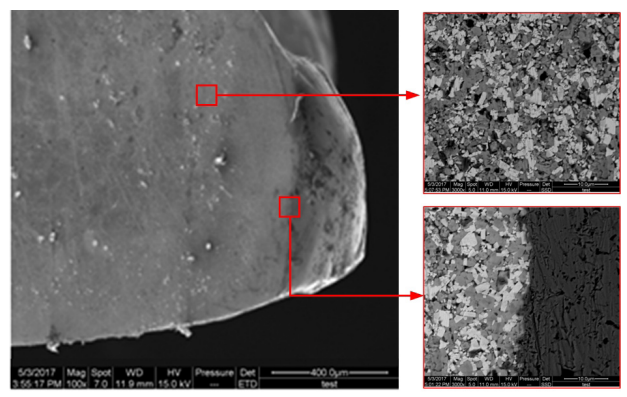

Fig. 6. The tool during adhesion

The analysis steps are as follows:

(1) Calculation of the volume fraction of each phase

Because the cemented carbide is opaque, one cannot directly observe the composition and the three-dimensional spatial distribution of the phases, and they can only be estimated by observing the twodimensional microstructure images of the cemented carbide. The two-dimensional microstructure is shown in Fig. 7.

The basic equation of volumetric stereology is shown in Eq. (1):

$$
V_{V}=A_{A},
$$

where $V_{V}$ is the volume ratio of the measured tissue in the three-dimensional space and $A_{A}$ is the area ratio of the measured tissue in the two-dimensional image. 


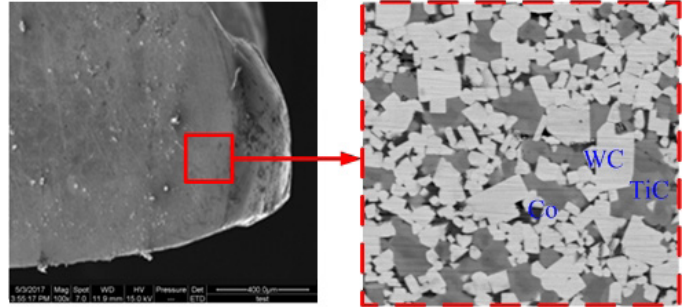

Fig. 7. The two-dimensional microstructure image of the YT5 tool

According to the stereology theory, the volume fraction of each phase in the cemented carbide can be determined by the area of the phase in the cross-section, the percentage of the cross-sections, or the number of observation points. To obtain a relatively accurate area ratio of each phase in the two-dimensional image, the volume fraction of each phase in the cemented carbide was measured using the Image J software and the area method. The image of the microstructure of the YT5 tool is binarized and denoised. In the binary image, the grayscale values range from 0 to 255, where 0 represents black, and 255 represents white. The measurements of the Co and $\mathrm{WC}$ phase volume fraction using the grayscale image is shown in Fig. 8. The measurements do not include the volume fraction of the impurities and pores in the cemented carbide, and it is assumed that the cemented carbide contains only $\mathrm{WC}, \mathrm{TiC}$, and $\mathrm{Co}$ phases. The volume fraction of the $\mathrm{WC}, \mathrm{Co}$ and $\mathrm{TiC}$ phases in the cemented carbide tool can be obtained from the measured average grayscale values.
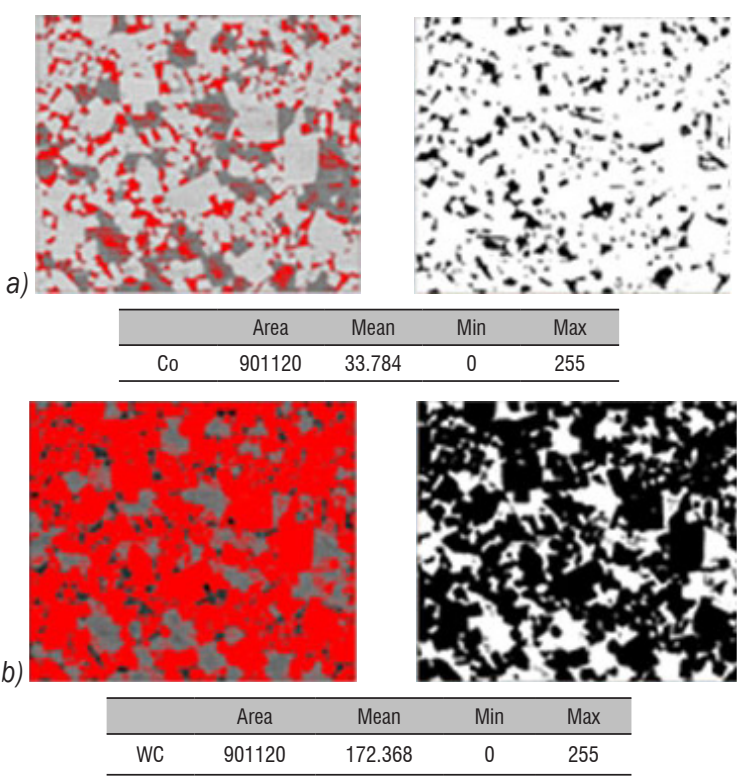

Fig. 8. Co and WC phase volume fractions measurements of the YT5 tool; a) Co, and b) WC
(2) Calculation of the average grain size of WC and $\mathrm{TiC}$

The microstructure image of the YT5 tool is also used to measure the average grain size, as shown in Fig. 9. Because the difference between the WC and TiC grain size is not easy to determine, the average grain size of the two phases is obtained and used as the overall grain size assuming that the grain size is the same for WC and TiC. The grains of the two phases are separated and calibrated using the Image $\mathrm{J}$ software, and the area and perimeter of the average grain size of $\mathrm{WC}$ and $\mathrm{TiC}$ are determined, ignoring the small-size grains. The circular diameter and the shape factor of the grains are calculated based on the area and the circumference. The calculations are shown in Eqs. (2) and (3):

Equivalent circle diameter:

$$
d=2 \times \sqrt{\frac{A}{\pi}},
$$

grain shape factor:

$$
S=\frac{4 \pi A}{L^{2}},
$$

where $A$ is the area occupied by the grains and $L$ is the grain perimeter.
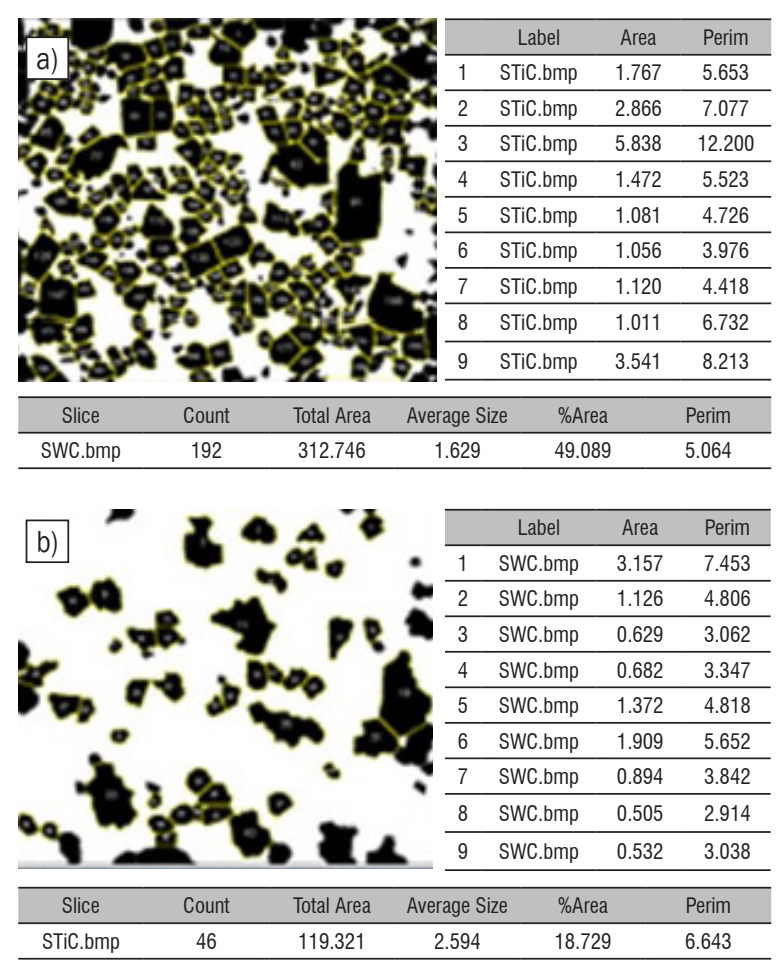

Fig. 9. WC and TiC phase area and circumference measurements of the YT5 tool; a) WC, and b) TiC 
(3) Calculation of grain adjacency

It is assumed that the grains of $\mathrm{WC}$ and $\mathrm{TiC}$ have the same average size and shape. The adjacency of the grains is calculated, and it is assumed that there are only two phases in the tool material; the first is the a phase and includes $\mathrm{WC}$ and $\mathrm{TiC}$ and the second is the $\mathrm{b}$ phase, and it includes only Co. The adjacency is calculated using Eq. (4) [20]:

$$
c=\frac{2 \sum_{i} L_{\mathrm{aa}}^{i}}{2 \sum_{i} L_{\mathrm{aa}}^{i}+2 \sum_{j} L_{\mathrm{ab}}^{j}},
$$

where $L_{\mathrm{aa}}$ is the phase boundary length between the grains of phase a and phase a in the two-dimensional image; $L_{\mathrm{ab}}$ is the phase boundary length of phase a and $\mathrm{b}$ in the two-dimensional image.

The Co phase was binarized using Image $\mathrm{J}$ software for the perimeter measurements, as shown in Fig. 10; the small areas are ignored, and the sum of the perimeters $\sum_{j} L_{\mathrm{ab}}^{j}$ is calculated. Similarly, the sum of the grain perimeters of $\mathrm{WC}$ and $\mathrm{TiC}$ $2 \sum_{i} L_{\mathrm{aa}}^{i}+2 \sum_{j} L_{\mathrm{ab}}^{j}$ is calculated. Then, the adjacency is calculated using Eq.(4).

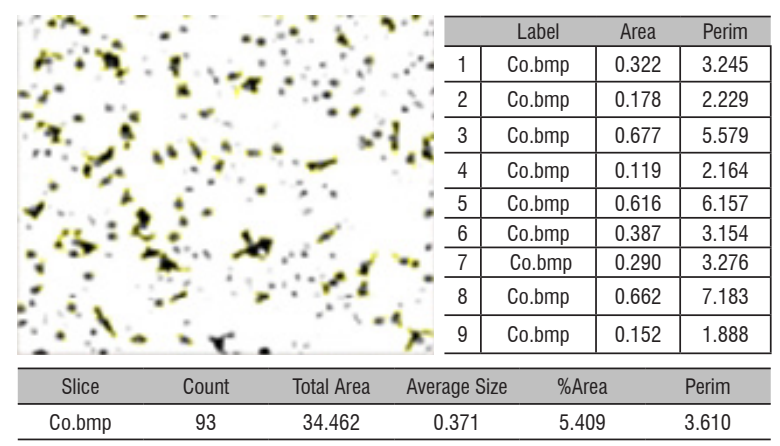

Fig. 10. Co-phase area and circumference measurements of the YT5 tool

The YT5 tool material parameters that were obtained using these equations are shown in Table 2.

Table 2. Main components of the YT5 cemented carbide tool

\begin{tabular}{lccc}
\hline Components & TiC & WC & Co \\
\hline Volume fraction & 19.15 & 67.60 & 13.25 \\
\hline Content [wt\%] & 7.43 & 83.41 & 9.16 \\
\hline Average grain size $[\mu \mathrm{m}]$ & \multicolumn{3}{c}{1.41} \\
\hline Adjacency & \multicolumn{3}{c}{0.74} \\
\hline
\end{tabular}

According to the material parameters of tool YT5 in Table2, the three-dimensional microstructure model of cemented carbide is established in ABAQUS. The modelling process is shown in the following Fig. 11.

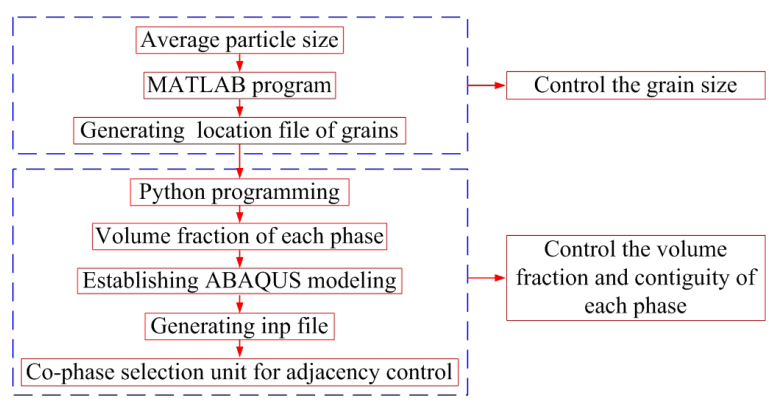

Fig. 11. Flow-chart for establishing the three dimensional micro model of the cemented carbide

In the simulation, a model size of $3 \mu \mathrm{m} \times 3 \mu \mathrm{m}$ $\times 3 \mu \mathrm{m}$ was used. To simulate the crack formation, a layer of cohesive elements was placed between the contact surfaces of the two consecutive (bulk) parts. Each phase unit consists of C3D4 elements, and the cohesive unit consists of COH3D6 elements, as shown in Fig. 12. The model of the crack propagation on the cemented carbide is established by inserting the cohesive unit, as shown in Fig. 13.
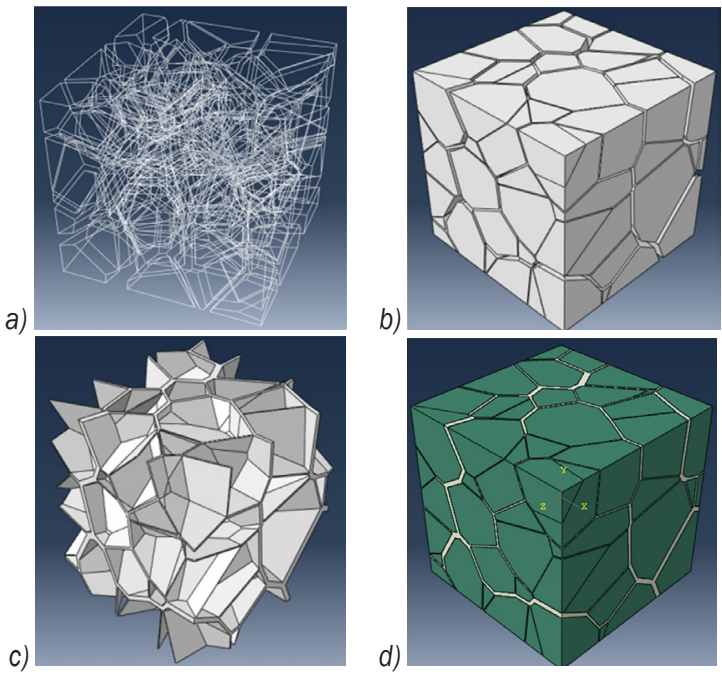

Fig. 12. ABAQUS modelling process; a) create a particle frame, b) build particle surface and body, c) insert the Co phase, and d) micro model of cemented carbide tool rake face

\subsection{Constitutive Model of Cohesive Unit}

The cohesive unit in ABAQUS uses the tractionseparation law as the constitutive model [21], including the damage initiation criteria and damage evolution settings. The maximum stress $\left(T_{\max }\right)$ and fracture energy $\left(G_{\mathrm{TC}}\right)$ are chosen here as the fracture criteria because the material is a brittle material, as shown in Fig. 14. Before damage occurs to the cohesive unit, the unit is in the elastic stage, and the 
a)

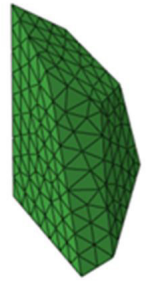

b)

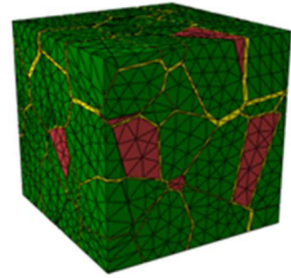

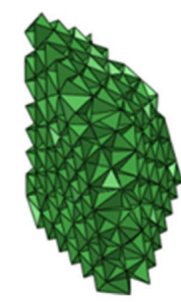

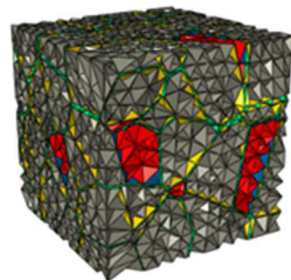

Fig. 13. Particles and integral models embedded in cohesive units; a) particles and its cohesive units, and b) integral models and their cohesive units

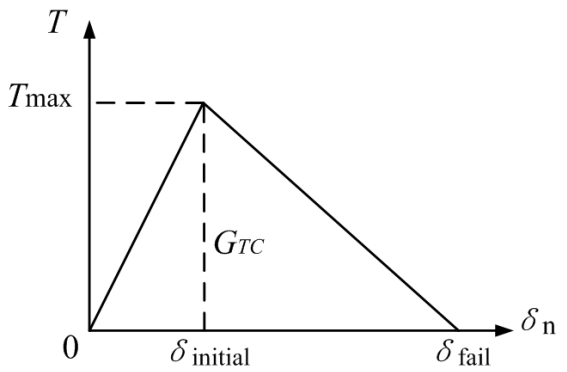

Fig. 14. Typical traction-separation response

elastic modulus at this stage is called the penalty stiffness $\left(K_{\mathrm{n}}\right)$. When the unit is subjected to tension, the two separate surfaces of the unit exhibit relative displacement, leading to the continuous increase in the internal stress. When the set maximum stress $\left(T_{\max }\right)$ is reached, the cohesive unit begins to enter the damage stage, and the unit's stiffness starts to degrade. The stiffness of the cohesive unit in the degradation stage is quantified by ABAQUS and a damage degradation coefficient $D$ is introduced. $D=0$ indicates that the unit has not been damaged yet and $D=1$ means that the unit's stiffness has reached zero, i.e., the unit fails, and the crack propagates. ABAQUS provides three types of stiffness degeneration: linear, exponential, and tabular; the linear stiffness degeneration is chosen here. From the bilinear criteria shown in Fig. 14, The calculations of $G_{\mathrm{TC}}$ and $K_{\mathrm{n}}$ are shown in Eqs. (5) and (6):

$$
\begin{gathered}
G_{\mathrm{TC}}=\frac{T_{\max } \cdot \delta_{\text {fail }}}{2}, \\
K_{\mathrm{n}}=\frac{T_{\max }}{\delta_{\text {initial }}},
\end{gathered}
$$

where $\delta_{\text {initial }}$ is the displacement of the unit at the beginning of the damage stage; $\delta_{\text {fail }}$ is the displacement of the unit at complete failure; $G_{\mathrm{TC}}$ is the energy required during the failure process.

ABAQUS controls the damage and fracture behaviour of the cohesive unit by setting the three parameters of $K_{\mathrm{n}}, T_{\max }$, and $G_{\mathrm{TC}}$. Because of the characteristics of the parameters in the cohesive unit, it is difficult to obtain the accurate values of these parameters using the experimental method; this is one of the main factors restricting the development of the cohesive unit. Gren established a molecular dynamics model of WC particles and analysed the binding energy of two adjacent WC particles and the binding energy when Co was present; the results showed that the binding energy of two particles was smaller in the presence of Co. The parameters of the cohesive unit used in this study are based on the studies of Gren, in which the internal binding energy of the grains was $5.76 \mathrm{~J} / \mathrm{m}^{2}$, the binding energy at the grain boundary was $3.2 \mathrm{~J} / \mathrm{m}^{2}$, and the binding energy of the particles including Co was $2.7 \mathrm{~J} / \mathrm{m}^{2}$ [22]. The maximum tensile stress of the cohesive unit is $T_{\max }$, which is generally assumed to be part of Young's modulus of the material. Typically, the value of $T_{\max }$ ranges from 0.1 $\%$ to $1 \%$ of Young's modulus [23] and [24]. In this study, a value of $T_{\max }=0.002 \times E$ is chosen. The values of Young's modulus of the phases corresponding to the $T_{\max }$ values of the different phase are obtained from [25], and the specific parameters are shown in Table $3 . K_{\mathrm{n}}$ is the penalty stiffness of the cohesive unit and differs from the inherent elastic modulus of the material. To ensure that the embedded cohesive unit does not affect the overall model stiffness, $K_{\mathrm{n}}$ needs to be sufficiently large, but when the value is too large, it affects the computational efficiency of the model. The value of $K_{\mathrm{n}}$ is usually calculated by the ratio of $\delta_{\text {initial }}$ and $\delta_{\text {fail }}$, which is 0.001 in this study based on Eqs. (5) and (6).

Table 3. The values of Young's modulus of the phases corresponding to the Tmax values

\begin{tabular}{lcc}
\hline Phase & WC & Co \\
\hline Young's Modulus [GPa] & 696 & 211 \\
\hline
\end{tabular}

\subsection{Boundary Condition}

During the cutting process, the contact area of the chips and tool is divided into a close contact area and a peak contact area; the stress state of the tool material in these two regions is not the same because of the adhesion effect. In the close contact area, the wear 
of the rake face occurs mainly during the continuous cutting process, whereas in the intermittent cutting process, the chips remain on the rake face due to the adhesion effect in this region when the tool is cutting. The material in this area of the tool is subject to the shear force resulting from friction with the chips. In the peak contact area, the chips are about to separate from the rake face due to upward curling and the tool material in this area is mainly subject to the tensile force that is perpendicular to the rake face as a result of the chip swing and the tool-chip adhesion.

\subsubsection{Reasons for the Removal of the Rake Face Material by the Chips}

(1) Since Fe and Co belong to the same family of elements, the tool and chips form a firm connection in the molten state of the workpiece material on the rake face;

(2) Because of the effects of high temperature and high pressure, element diffusion occurs between the tool and the workpiece material and changes the composition of the tool material; this results in the decrease in the rake face strength.

(3) The hard phase of the rake face is broken due to the impact load on the rake face. Coupled with the high temperature of the chips, microcracks occur in the surface and sub-surface layer of the rake face, resulting in the decrease in the tool strength.

\subsubsection{Location of the Adhesion Failure on the Rake Face}

(1) The location of the adhesion failure is in the close contact area between the chip and rake face and the contact area is subject to high temperature and pressure. During intermittent cutting, a strong connection between the tool and chips occurs readily, and the material of the rake face is rapidly removed by the chips as a result of frequent cutting in and cutting out.

(2) The location of the adhesion failure is in the contact area where the chips leave the rake face. Because of chip curling and frequent oscillation of the chips during curling, the material of the rake face in this region is subject to the periodic tensile stress of the chips, coupled with temperature changes during the swing process. Tool failure or breakage can easily occur because cemented carbide tools are resistant to compression but cannot bear the tension.

\subsubsection{Force Analysis of Tool-Chip Adhesion}

(1) Removal of material in the close contact area As shown in Fig. 15, the material of the rake face is peeled off from the close contact area and is subject to $F_{\mathrm{f}}$ in the same direction as the chip flow and the normal positive pressure $F_{\mathrm{n}}$ of the material (the resultant force of the positive pressure during the cutting process and the positive pressure of the material inside the tool; when the positive pressure in the internal material of the tool is larger than that during the cutting process, the peeling of the material occurs). $F$ is the resultant force in this area. Because of the large compressive stress applied to the peeled area, the friction force is relatively large. During the intermittent cutting process, the temperature difference solidifies the joints between the tool and chips, thereby increasing the friction. The external force at this site is only the friction force $F_{\mathrm{f}}$ between the chip and the rake face; the direction of this force is parallel to the rake face, and the material of the rake face is easily removed.

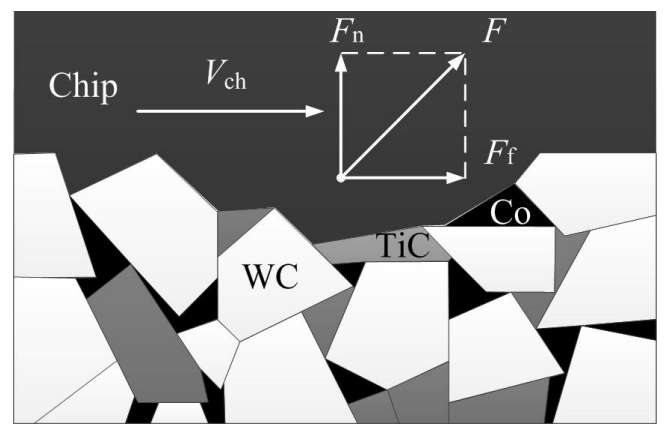

Fig. 15. Force analysis of tool-chip adhesion in the close contact area

(2) Removal of material in the area where the chips are about to separate from the rake face

As shown in Fig. 16, when the chip material is about to leave the rake face, the peeled area is subject to the frictional force of the chips $F_{\mathrm{f}}$ and the tensile force $F_{\mathrm{t}}$. Because the chip material on the rake face has a small positive pressure and the frictional force of the chips is much smaller in the peeled area than in the close contact area, a firm connection is formed between the tool and the chip material due to adhesion. The chip material generates a greater tensile force on the peeled area during the periodic swings; therefore, when the two external forces are combined, the direction of the force is almost perpendicular to the rake face, and the rake face material is easily removed due to the influence of the periodic tensile stress. 
Based on the results of the force analysis of the adhesion layer on the rake face, two kinds of force models are used in this study. The first model is created based on the force of the adhesion layer in the close contact area, and the shear force parallel to the rake face is applied to the rake face, as shown in Fig. 17a; the direction of tangential displacement is forward along the Y-axis. The second model is created based on the adhesion layer of the future separation area between the rake face and the chip, and the tensile load is applied to the rake face, as shown in Fig. 17b; the direction of tension displacement is negative along the $\mathrm{X}$-axis (red is the $\mathrm{X}$-axis, green is the $\mathrm{Y}$-axis, and blue is the $\mathrm{Z}$-axis).
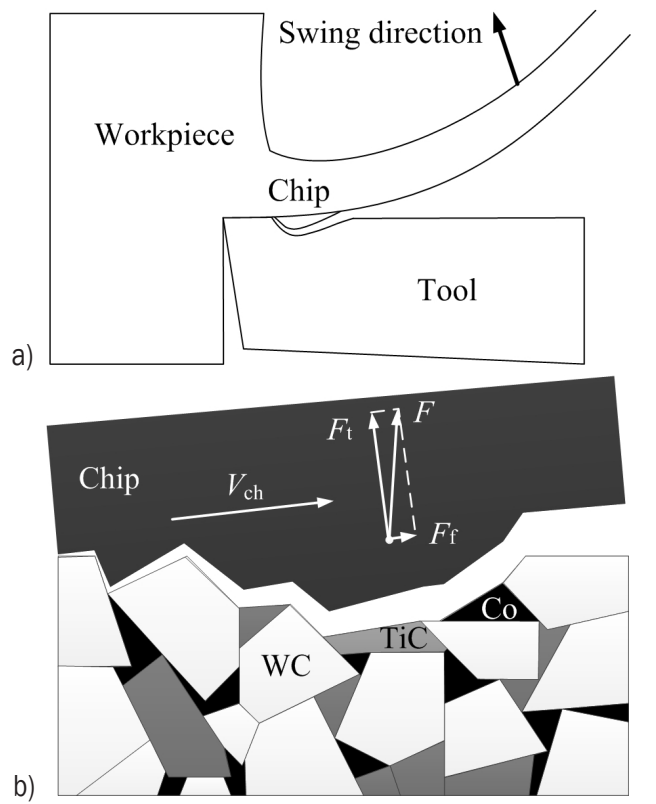

Fig. 16. Force analysis of the adhesion layer when the chips are removed from the rake face; a) schematic diagram of bond failure on the rake face during the cutting process, and b) the force condition of the cutting tool during the cutting process a)

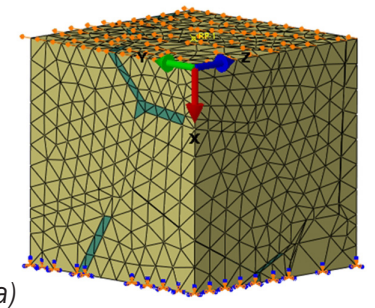

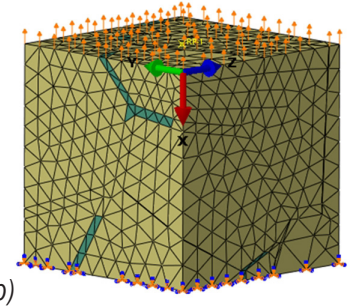

b) a) tangential displacement, and b) tensile displacement

\section{SIMULATION RESULTS OF THE CRACK PROPAGATION}

During the generation of the adhesion layer, the diffusion of the elements between the tool and the chip material affects the bonding strength between the constituent phases of the tool. Surface cracks also occur in the tool due to the thermal effect and affect the bond breakage behaviour of the tool. Therefore, the effects of the bonding strength of the different phases and the presence of initial cracks on the crack propagation are investigated.

\subsection{Crack Propagation Based on Cohesion}

The diffusion behaviour between the tool and chips affects the cohesive strength of the tool material, which influences the crack propagation path. Thus, the cohesive strength at the interface reflects the effect of the element diffusion on the crack propagation of the cemented carbide. It is generally assumed that the cohesive strength is lower than the grain strength. In this study, the cohesive strength is set to four levels that are $0.7,0.8,0.9$, and 1.0 times the original cohesive strength. The grain fracture energy $G_{\mathrm{TC}}$ of the transgranular fracture can be expressed as [26]:

$$
G_{\mathrm{TC}}=\gamma_{\mathrm{s}},
$$

where $\gamma_{\mathrm{s}}$ is the surface energy of the matrix grain per unit area $\left[\mathrm{J} / \mathrm{m}^{2}\right]$.

When the Co structure is close-packed hexagonal (hcp), $\gamma_{\mathrm{s}}$ is $2.55 \mathrm{~J} / \mathrm{m}^{2}$ [27]. In the cemented carbide, the Co structure is face-centred cubic (fcc), which has better plasticity than the hcp structure; therefore, the Co fracture energy setting is $1 / 3$ larger than the reference value $\left(6.8 \mathrm{~J} / \mathrm{m}^{2}\right)$. This provides a more realistic model. The specific parameters are shown in Table. 4.

The simulation results under different cohesive strength are shown in Fig. 18. The simulation diagram indicates that the crack propagation paths extend along the WC-Co interface and the WC-WC interface under the four types of cohesive strength. When the cohesive strength is 0.7 times and 0.8 times the cohesive strength of the particles, the crack propagation path, which extends along the bonding surface with a relatively weak cohesive strength, is basically the same and the crack propagation surface is perpendicular to the load direction. When the cohesive strength is 0.9 times the cohesive strength of the particles, the crack propagation path is deflected around the stronger bonding surface due to the increase in the cohesive strength between the local 
particles. When the cohesive strength is 1.0 times the cohesive strength of the particles, the edges of the local particles are fragmented due to the local increase in the cohesive strength between the particles.

Table 4. Parameters of the cohesive strength

\begin{tabular}{|c|c|c|c|c|}
\hline $\begin{array}{c}\text { Type } \\
\text { of } \\
\text { cohesive } \\
\text { units } \\
\end{array}$ & Grade & 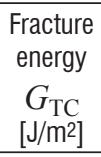 & $\begin{array}{c}\text { Maximum } \\
\text { stress } \\
T_{\max } \\
{[\mathrm{GPa}]} \\
\end{array}$ & $\begin{array}{c}\text { Penalty } \\
\text { stiffness } \\
K_{\mathrm{n}} \\
{[\mathrm{GPa} / \mathrm{m}]}\end{array}$ \\
\hline \multirow{16}{*}{$\begin{array}{c}\text { WC } \\
\text { Co } \\
\text { WC-WC } \\
\text { WC-Co }\end{array}$} & \multirow{4}{*}{0.7} & 5.76 & 1.39 & $1.68 \times 1011$ \\
\hline & & 6.8 & 0.42 & $1.30 \times 1010$ \\
\hline & & 3.2 & 0.97 & $1.47 \times 1011$ \\
\hline & & 2.7 & 0.29 & $1.56 \times 1010$ \\
\hline & \multirow{4}{*}{0.8} & 5.76 & 1.39 & $1.68 \times 1011$ \\
\hline & & 6.8 & 0.42 & $1.30 \times 1010$ \\
\hline & & 3.2 & 1.112 & $1.93 \times 1011$ \\
\hline & & 2.7 & 0.336 & $2.09 \times 1010$ \\
\hline & \multirow{4}{*}{0.9} & 5.76 & 1.39 & $1.68 \times 1011$ \\
\hline & & 6.8 & 0.42 & $1.30 \times 1010$ \\
\hline & & 3.2 & 1.251 & $2.45 \times 1011$ \\
\hline & & 2.7 & 0.378 & $2.65 \times 1010$ \\
\hline & \multirow{4}{*}{1.0} & 5.76 & 1.39 & $1.68 \times 1011$ \\
\hline & & 6.8 & 0.42 & $1.30 \times 1010$ \\
\hline & & 3.2 & 1.39 & $3.02 \times 1011$ \\
\hline & & 2.7 & 0.42 & $3.27 \times 1010$ \\
\hline
\end{tabular}

a)

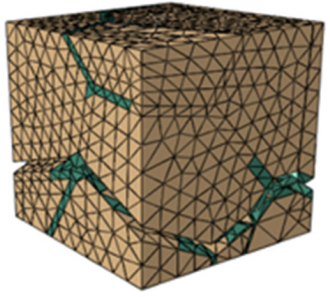

c)

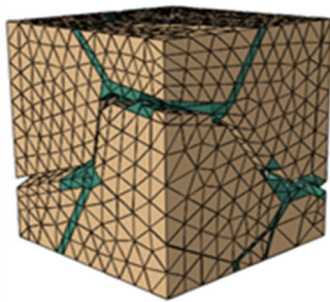

b)
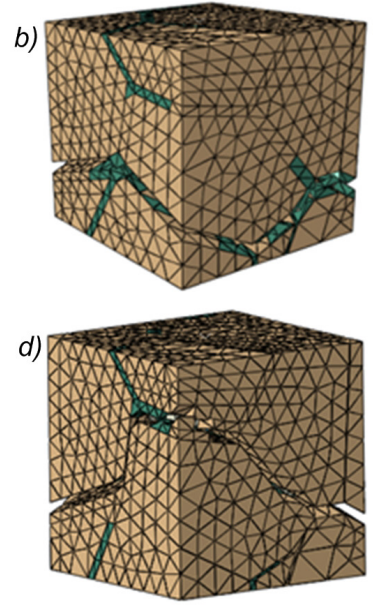

Fig. 18. Crack propagation path within the unit cells under tensile displacement for different cohesive strength; a) 0.7 times, b) 0.8 times, c) 0.9 times, and d) 1.0 times

The crack propagation through the WC particles does not occur during the simulation process, and the initial crack is enlarged as shown in Fig. 19. The cracks initiate from the WC-Co interface and extend to the WC-WC interface in the tensile state. When the WC-WC interface strength is equal to or slightly less than the particle strength, the direction of the crack propagation is locally deflected; however, due to the occurrence of multiple cracks, the crack still expands and bridges along the relatively weak interface of the cohesive strength, eventually resulting in a fracture.

a)
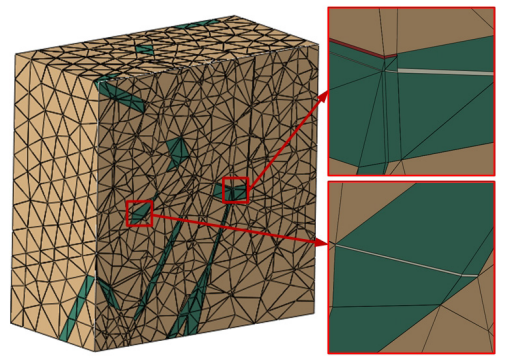

b)

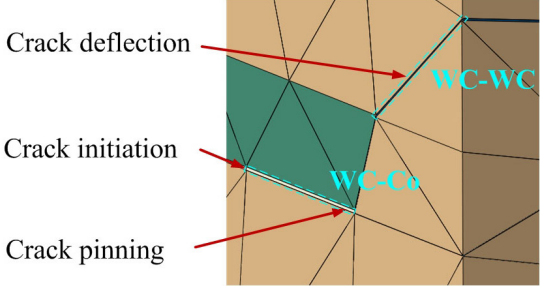

Fig. 19. Crack initiation and propagation; a) crack initiation, and b) crack propagation

\subsection{Crack Propagation in the Absence of an Initial Crack}

The simulation model is used in the ABAQUS display solver for analysis and calculation. The crack propagation paths of the model under different modes of loading are shown in Figs. 20 and 21. The crack propagation under a friction load imposed by applying a tangential displacement to the cemented carbide rake face is shown in Fig. 20, and the crack propagation under tensile displacement is shown in Fig. 21. The stress unit in Figs. 20 and 21 is $10^{3} \mathrm{GPa}$.

According to Griffith's crack propagation theory [28], the crack initiation usually occurs in a material with internal defects or weak internal strength and cracks always propagate along the direction of highest energy dissipation. As can be seen from Figs. 20 and 21 , the process of crack initiation is well simulated by the model. The crack initiation sites in the model are located at the WC-Co grain boundary where the cemented carbide is weakly bonded, and the crack propagation path is along the two-phase interface. The crack surface is perpendicular to the applied load direction, which is consistent with the results obtained by previous research [5]. At the same time, the changes in the stress during the crack propagation can be observed, and the maximum stress increases with the crack growth due to the extrusion deformation of the local grid. In the model without the presence of cracks, the stress distribution is not uniform under a 
a)

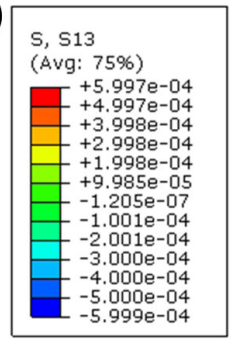

c)

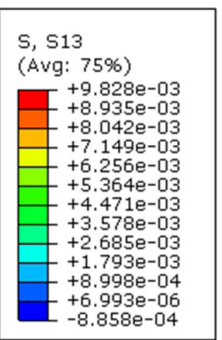

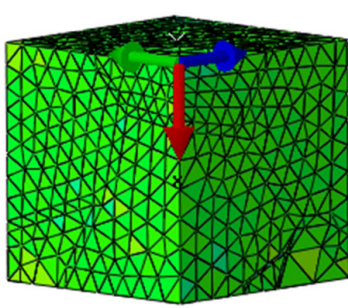

b)
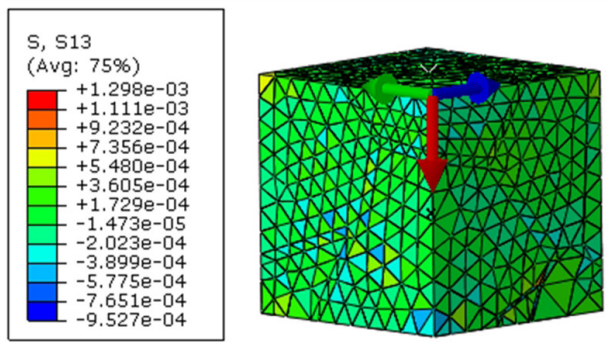

d)

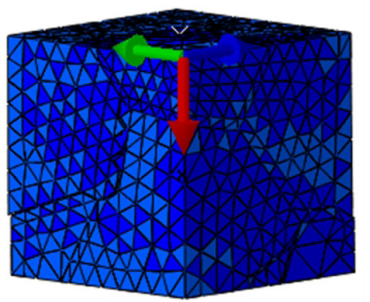

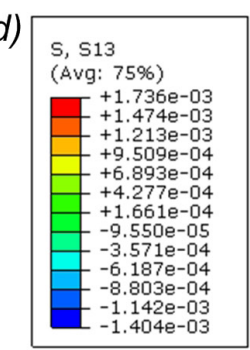

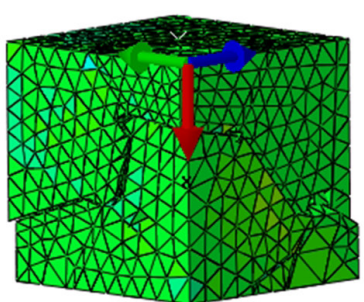

Fig. 20. Crack propagation under the effect of a tangential displacement; a) initial state, b) crack initiation, c) crack propagation, and d) final fracture

a)

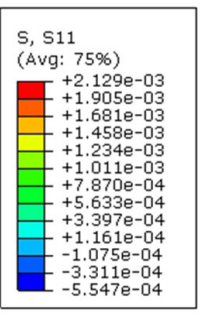

c)

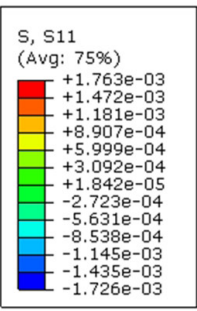

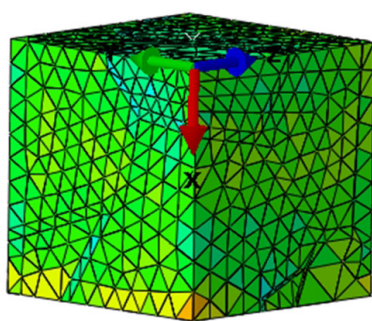

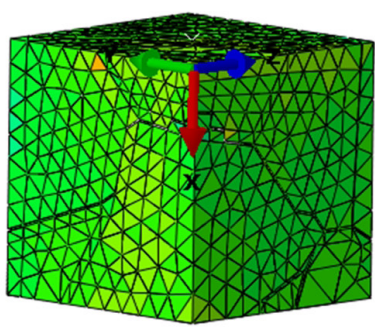

b)

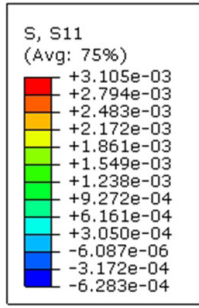

d)

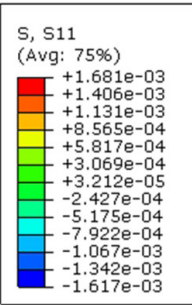

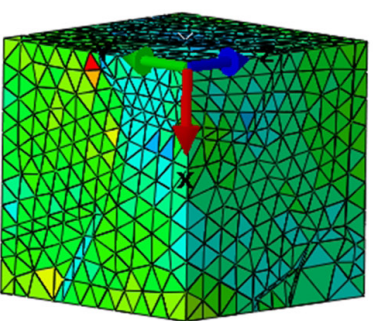

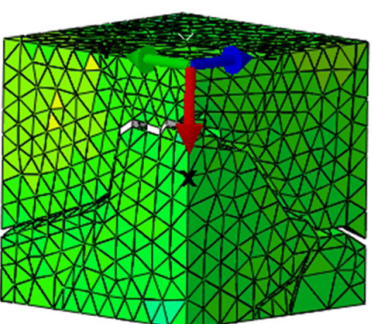

Fig. 21. Crack propagation under the effect of a tensile displacement;

a) initial state, b) crack initiation, c) crack propagation, and d) final fracture

load, and the stress in the binder phase is generally lower. In contrast, in the model where cracks are present, the stress distribution tends to be uniform in most regions of the model, except for the part of the grid with the highest stress due to over-deformation.

\subsection{Crack Propagation in the Presence of Initial Cracks}

The rake face of the carbide tool is prone to cracking under the conditions of high temperature and high pressure, and the cracks on the tool rake face may occur in the $\mathrm{WC}$ particles, the $\mathrm{WC}-\mathrm{WC}$ bonding surface, and the WC-Co bonding surface. A simulation is conducted to systematically investigate the effect of the crack location on the crack propagation path in the cemented carbide. We focus on the adhesive layer produced by the rake face during the cutting process of the carbide tool and the peeling of the adhesive layer during the chip removal is simulated and analysed. Subsequently, cracks are added to the model, and the simulation study is conducted for two different crack locations. 


\subsubsection{Single Crack}

\subsubsection{Crack Location in the WC Particles}

(1) The position, angle, and load direction of the prefabricated crack are shown in Fig. 22. The crack is located in the WC particles, and the length is about half the average size of the WC particles. Three cases of crack directions are investigated. In the first case, the crack surface is parallel to the rake face; in the second case, the crack plane is $45^{\circ}$ to the rake face; in the third case, the crack surface is perpendicular to the rake face. The results of the crack propagation for the three cases are shown in Fig. 23. It is evident that the crack propagation process is similar when the prefabricated crack plane forms an angle of $0^{\circ}$ and $45^{\circ}$ with the rake face. The crack first expands from the WC-Co interface and the prefabricated cracks and then forms multiple cracks; subsequently, the cracks join and eventually create fractures, which are transgranular and intergranular fractures. When the prefabricated crack plane is perpendicular to the rake face, the prefabricated crack has little effect on the crack propagation path and the crack propagates from the WC-Co interface and the WC-WC interface without passing through the $\mathrm{WC}$ particles.

(2) As shown in Fig. 24, a tangential load is applied in the model of the prefabricated crack. It can be seen from Fig. 25 that the crack propagation path is more sensitive to the $0^{\circ}$ and $45^{\circ}$ cracks and the propagation path of the crack passes through the two kinds of prefabricated cracks, whereas for the $90^{\circ}$ crack, the prefabricated crack has little effect on the crack propagation path.

By comparing Fig. 25 and Fig. 20, Fig. 23 and Fig. 21 respectively, it turns out that when there
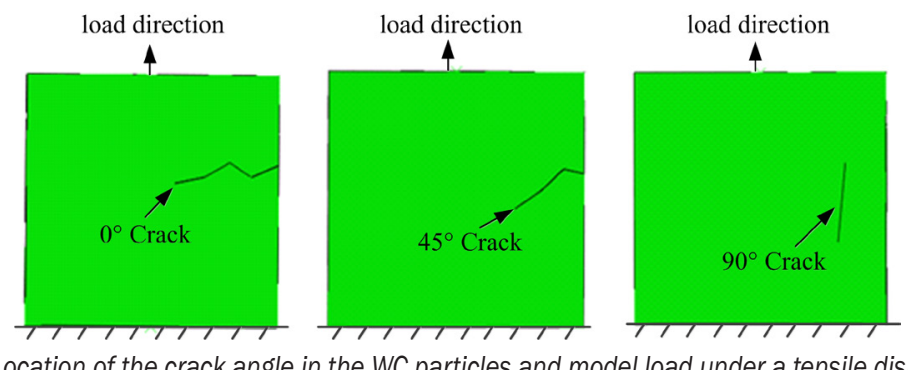

Fig. 22. Location of the crack angle in the WC particles and model load under a tensile displacement

a)

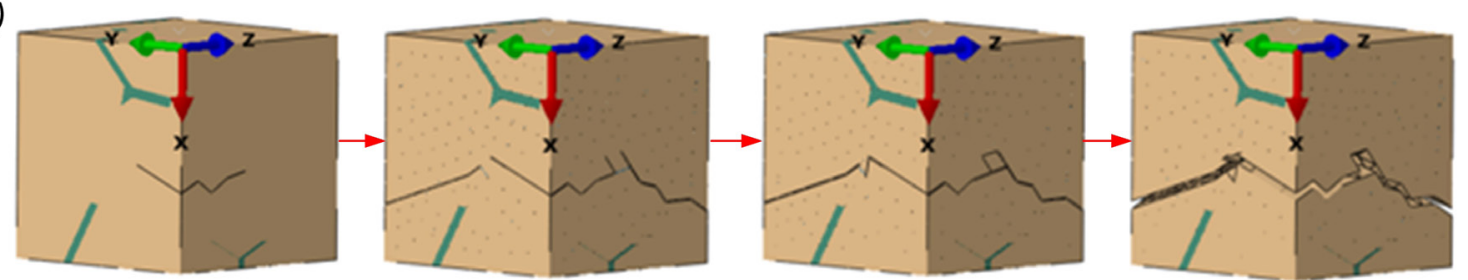

\section{b)}
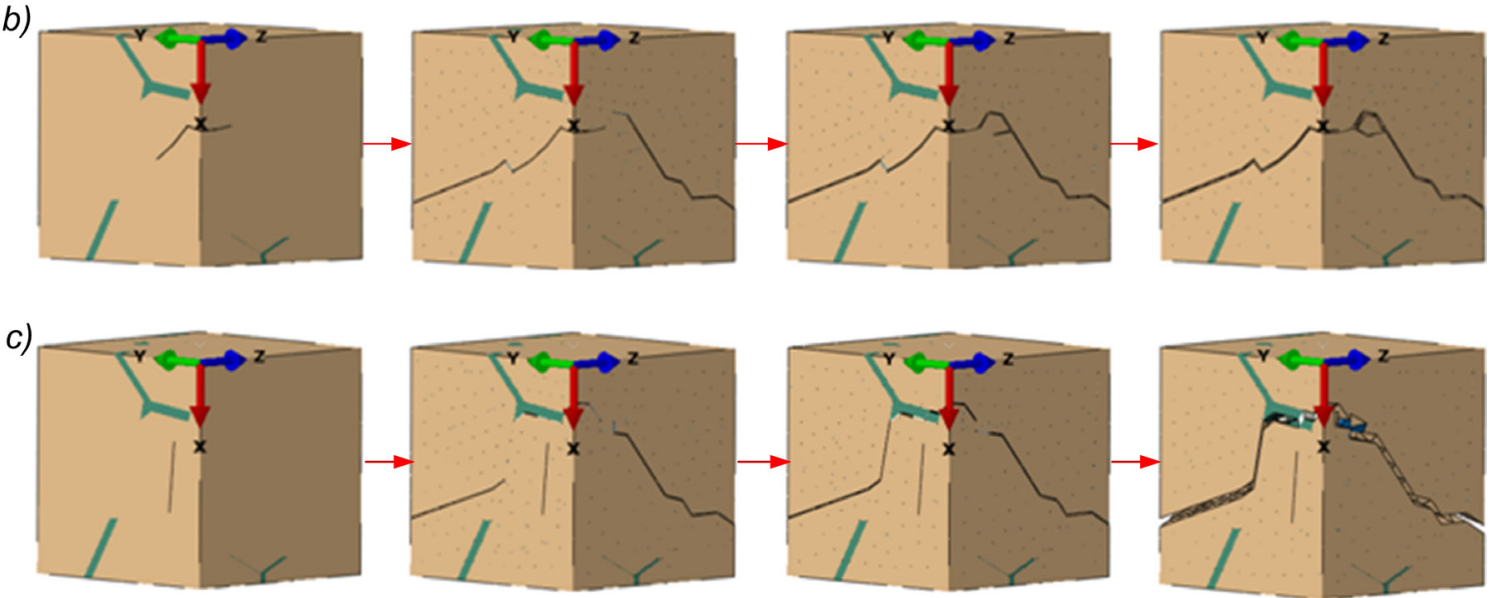

Fig. 23. Crack propagation under a tensile displacement: a) $0^{\circ}$ crack, b) $45^{\circ}$ crack, and c) $90^{\circ}$ crack 


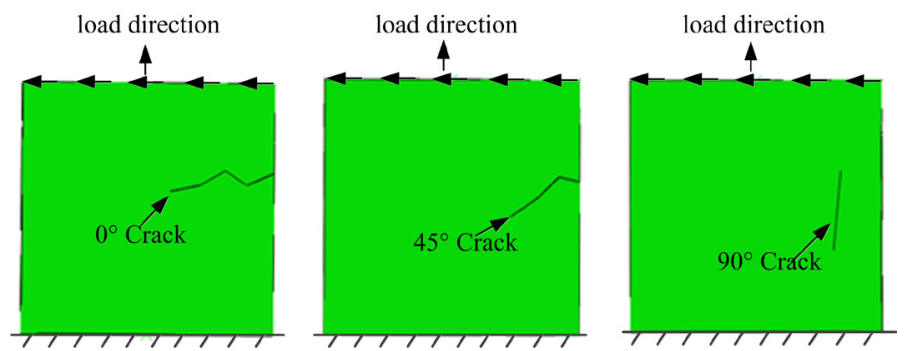

Fig. 24. Location of the crack angle in the WC particles and model load under a tangential displacement

a)
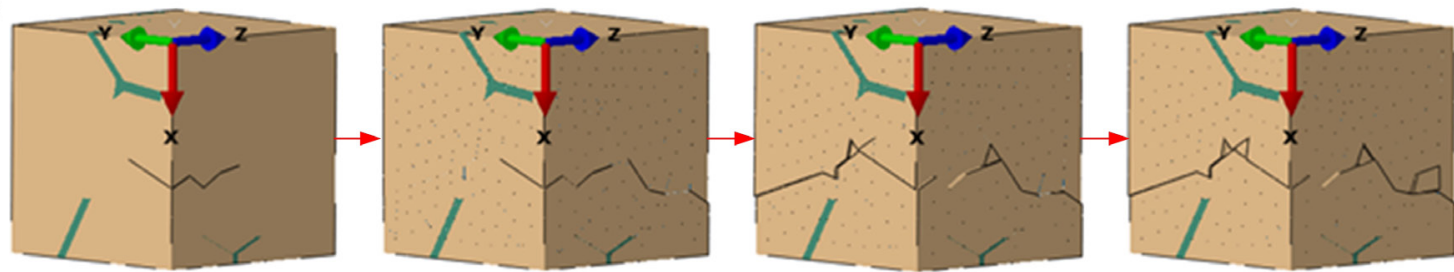

b)
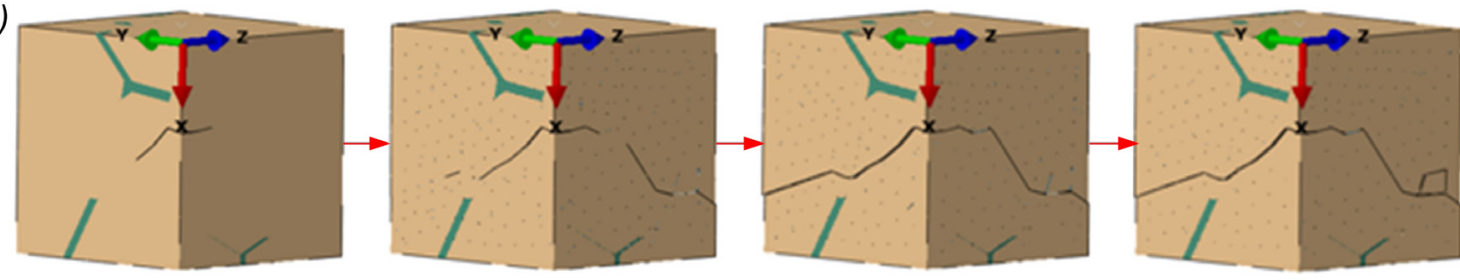

c)
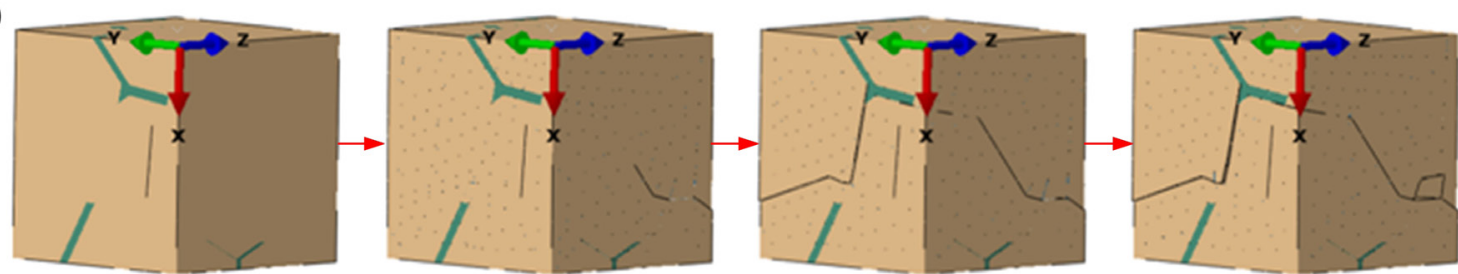

Fig. 25. Crack propagation under a tangential displacement: a) $0^{\circ} \mathrm{crack}$, b) $45^{\circ} \mathrm{crack}$, and c) $90^{\circ} \mathrm{crack}$

is a crack in the WC particles in the adhesive layer of the carbide tool rake face, the adhesive layer is peeled off under the combined action of friction and the tool-chip force. The direction of the initial crack has a significant influence on the crack propagation path, which in turn affects the peeling volume of the adhesive layer, i.e., the larger the peeling volume, the faster the tool failure rate is and the shorter the tool life is due to the bond breakage. The analysis of the simulation results shows that the initial crack surface that is parallel to the rake face or at an angle of $45^{\circ}$ to the rake face has a greater impact on the crack propagation path, whereas the initial crack that is perpendicular to the rake face has less of an effect on the crack propagation path.

\subsubsection{Crack Location at the WC-Co and WC-WC Interfaces}

As shown in Fig. 26, a uniaxial tensile load was applied to the model. The cracks are distributed at the WC-Co and WC-WC interfaces and mainly propagated along the grain boundaries. Fig. 26 shows

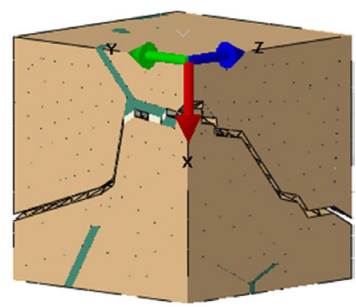

Fig. 26. Original crack propagation path 


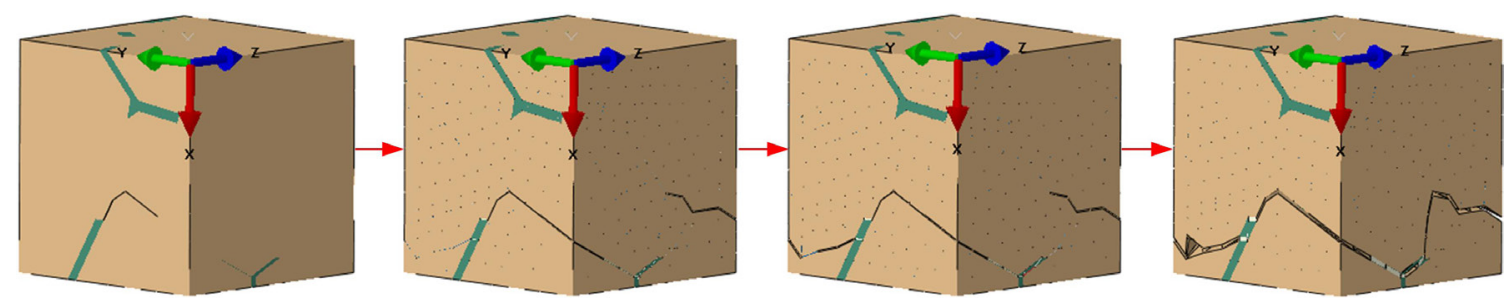

Fig. 27. Crack propagation paths of prefabricated cracks

the original crack propagation path. The intergrain cracks change the original crack propagation path, which can be seen from a comparison of Figs. 26 and 27.

\subsubsection{Multiple Cracks}

To further investigate the crack propagation paths, a number of prefabricated cracks are applied in the model to simulate the crack propagation for multiple cracks; Fig. 28 shows that $0^{\circ}, 45^{\circ}$, and $90^{\circ}$ cracks are applied in the model. A uniaxial tensile load is applied, and the simulation results are shown in Fig. 29.

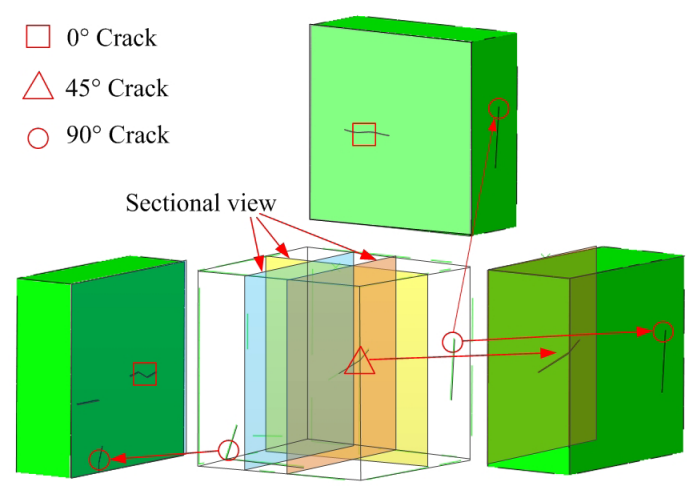

Fig. 28. Different crack distributions
The simulation results indicate that the crack propagation process is a self-expansion process of a single crack and the interconnection between the cracks. It can be seen from the fracture surface of the model that the crack propagation paths of multiple cracks pass through many prefabricated cracks. Although the crack perpendicular to the rake face is prefabricated in the WC particles, the crack still does not extend through the WC particles. For multiple cracks, the crack propagation path mainly passes through the prefabricated cracks at the WC-Co and WC-WC boundaries and due to the pinning action of the local particles, the cracks join, and the fracture occurs by bypassing the position with a higher bonding strength, resulting in the peeling of the adhesive layer.

A crack represents a form of energy release. When the energy inside the system accumulates to a certain extent and cannot be released, cracks reduce the energy and balance the system. The direction of crack propagation is in the direction of the highest energy dissipation. For uniform materials under a tensile load, the cracks tend to expand along the direction perpendicular to the load, whereas for composite materials, the crack propagation path is deflected and bypasses areas of higher bonding strength due to the local non-uniformity of the material; therefore, the energy is released more quickly.

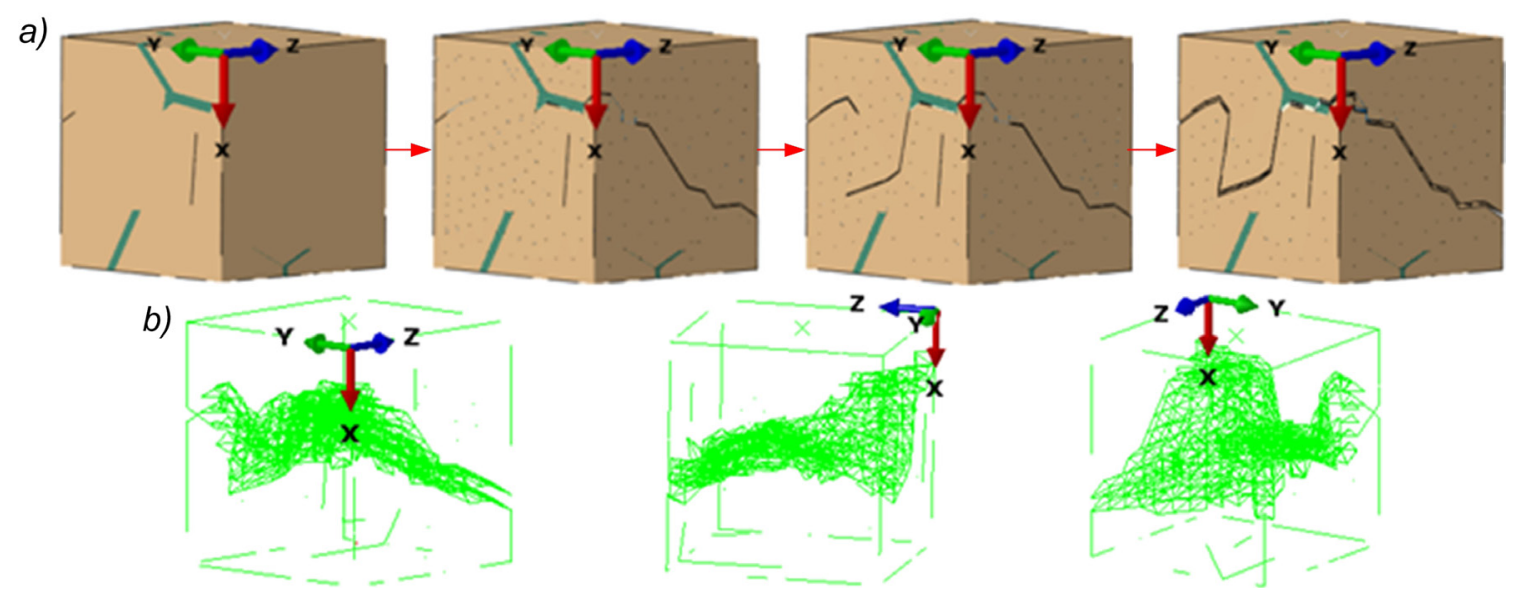

Fig. 29. Simulation results of multiple initial cracks; a) crack propagation process, and b) the fracture surface at different view angles 


\subsection{Effect of Crack on Tensile Strength}

As shown in Fig. 30, the tensile strength of the model under different cohesive strength values is analysed. The tensile strength of the model varies greatly for different cohesion values, and the tensile strength increases with the increase in the cohesive strength of the cemented carbide. Therefore, increasing the combined force of the two phases helps to increase the strength of the cemented carbide.

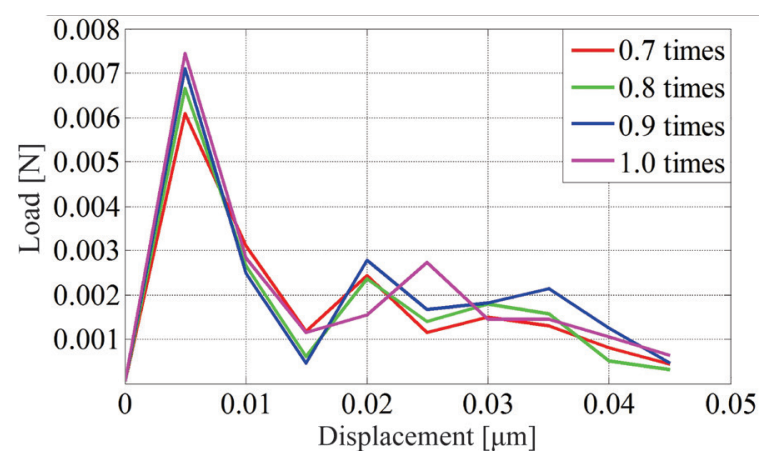

Fig. 30. Load-displacement curves of the unit cell under tensile load for different cohesive strength values

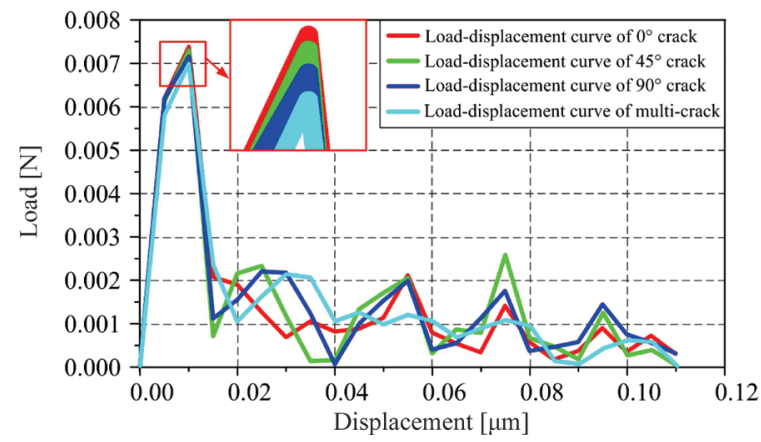

Fig. 31. Load-displacement curves of the unit cell under tensile load for different initial cracks

As shown in Fig. 31, the tensile strength in the presence of cracks is analysed in the model, and the maximum tensile load at the same position is obtained under different crack conditions. The differences in the tensile loads are small due to the small extent of the model. An analysis of the maximum tensile load shows that the presence of single cracks does not always reduce the tensile strength of the cemented carbide. Due to the stronger cohesive strength, the energy required for crack propagation is higher when the crack is in the interior of the particle and the local plastic zone at the tip of the crack has a pinning effect on the crack propagation. As a result, the tensile strength is increased and the maximum tensile load exhibits an overall increase. Due to the difference in the tensile and shear strengths of the particles, the tensile strength shows some differences for the different crack angles. Under normal circumstances, the probability of crack occurrence within the WC particles is small; therefore, this condition has a minimal effect on the tensile strength of the material and can be ignored. When multiple cracks exist initially, the cracks appear at the WC-Co and WC-WC boundaries, and the increase in the number of these cracks reduces the tensile strength of the cemented carbide, which makes the material more prone to fracturing under a tensile load.

\section{EXPERIMENTAL}

A SEM is used to observe the bond breakage of the tool and the surface morphology of the pits on the tool's rake face after the adhesive layer is peeled off; the results are shown in Fig. 32. It is evident that the surface of the WC particles in the tool is relatively intact and some of the particles are exposed; this shows that the form of adhesive layer peeling consists mainly of an intergranular fracture. This indicates that the experimental results are similar to the simulation result.

The location and the proportion of sub-surface cracks or holes in the carbide cutting tool face can be observed to determine the crack propagation path of the adhesive layer and roughly estimate the volume of the peeled-off material and the service life of the tool. This provides data for follow-up research.

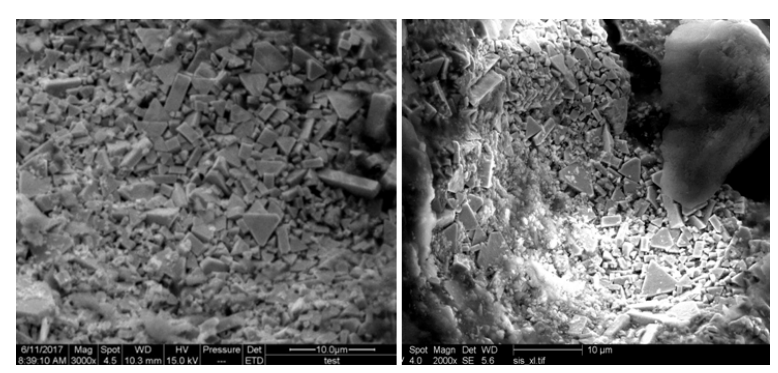

Fig. 32. Surface morphology after the peeling-off of the adhesion layer

\section{CONCLUSIONS}

Based on the simulation results and the tool-chip adhesion process, the following conclusions can be drawn:

(1) For different cohesive strength values, the cracks are deflected by the increase in the combined force of the local particles. In the absence of an initial crack, the inner crack of the carbide 
propagates along the bond plane of the WC-Co, and the crack propagation plane is generally perpendicular to the load direction.

(2) The bond breakage of the cemented carbide tool's rake face occurs in conjunction with the crack occurrence. For a single crack, the initial crack surface parallel to the rake face or at an angle of $45^{\circ}$ to the rake face has a large effect on the crack propagation path for the three types of initial cracks in the WC particles. When the initial crack is perpendicular to the rake face, there is only a small effect on the crack propagation path. For the cracks that are located in the WC-Co and WCWC interfaces, the initial crack mainly changes the original crack propagation path.

(3) When multiple cracks are present initially, the crack propagation path mainly passes through the prefabricated cracks and the WC-Co and WC-WC boundaries. Due to the pinning effect of the local particles, the cracks join and bypass the areas of high bonding strength to eventually produce a fracture, resulting in the peeling of the adhesion layer. The experimental results show that the particle surface is relatively intact after the cemented carbide is damaged, which indicates that an intergranular fracture occurred. This is consistent with the simulation results

(4) In the absence of cracks, the stronger the cohesive strength of the carbide, the greater the tensile strength of the material is. When there is a crack in the cemented carbide, the crack propagation and crack pinning increases the tensile strength of the material to some extent; however, the increase in the number of intergranular cracks reduces the overall tensile strength of the material, which makes the material more prone to fracture.

\section{ACKNOWLEDGEMENTS}

The authors would like to thank the support of the National Natural Science Foundation of China (Grant No.51575146) and the Education and Research Project for young and middle-aged teachers of Fujian Province (Grant No.JAT170506).

\section{NOMENCLATURES}

$\begin{array}{ll}A_{V} & \text { area ratio, [-] } \\ A & \text { area, }\left[\mu \mathrm{m}^{2}\right] \\ c & \text { grain adjacency, [-] } \\ d & \text { diameter, [ } \mu \mathrm{m}] \\ D & \text { damage degradation coefficient, [-] } \\ E & \text { Young's modulus, [GPa] }\end{array}$

$F \quad$ resultant force vector, $[\mathrm{N}]$

$F_{\mathrm{f}} \quad$ friction force, $[\mathrm{N}]$

$F_{\mathrm{n}} \quad$ normal positive pressure force, $[\mathrm{N}]$

$F_{\mathrm{t}} \quad$ tensile force, [N]

$G_{\mathrm{TC}} \quad$ fracture energy, $\left[\mathrm{J} / \mathrm{m}^{2}\right]$

$K_{\mathrm{n}} \quad$ penalty stiffness, $[\mathrm{GPa} / \mathrm{m}]$

$L \quad$ grain perimeter, $[\mu \mathrm{m}]$

$S \quad$ grain shape factor, [-]

$T_{\max } \quad$ max stress, [GPa]

$V_{\text {ch }} \quad$ cutting speed, $[\mathrm{m} / \mathrm{min}]$

$V_{V} \quad$ volume ratio, [-]

$\delta_{\text {initial }}$ the displacement at the beginning of the unit damage, $[\mu \mathrm{m}]$

$\delta_{\text {fail }}$ the displacement of the unit at the complete failure, $[\mu \mathrm{m}]$

\section{REFERENCES}

[1] Sun, F.L., Li, Z.J., Chen, B. (1997). Research on mechanism of adhering between chip and tool cutting $2.25 \mathrm{Cr}-1 \mathrm{Mo}$ steel. Journal of Harbin University Ofence \& Technology, vol. 2, no. 5, p. 1-3, DOl:10.15938/J.jhust.1997.05.001. (in Chinese)

[2] Cheng, Y.-N., Liu, X.-L., Li, Z.-J., Liu, L., Wang, H.T. (2012). Adhering failure of the tool-chip in the process of extremely heavy cutting. Chinese Journal of Mechanical Engineering, vol. 48, no. 19, p. 169-176, Dol:10.3901/JME.2012.19.169. (in Chinese)

[3] Tan, G.-Y., Liu, G.-J., Li, Z.-J., Liu, M.-J., Li, G.-H., Rong, Y.-M. (2004). 3D temperature field analysis and fuzzy comprehensive evaluation for milling insert with complex groove. Chinese Journal of Mechanical Engineering, vol. 40, no. 3, p. 106-110, D0l:10.3321/j.issn:0577-6686.2004.03.021. (in Chinese)

[4] Gurland, J. (1963). The fracture strength of sintered tungsten carbide-cobalt alloys in relation to composition and particle spacing. Transactions of the Metallurgical Society of AIME, vol. 227, p. 1146-1150.

[5] Editorial committee, Foreign cemented carbides. (1976). Foreign cemented carbides. Metallurgical Industry Press, Beijing. (in Chinese)

[6] Sigl, L.S., Exner, H.E. (1987). Experimental study of the mechanics of fracture in WC-Co alloys. Metallurgical Transactions A, vol. 18, no. 7, p. 1299-1308, D0l:10.1007/ BF02647199.

[7] Ljungberg, A. B., Chatfield, C., Hehenberger, M., Sundstrom, B. (1986). Estimation of the plastic zone size associated with cracks in cemented carbides. Proceedings of the Second International Conference on the Science of Hard Materials, p. 619-630.

[8] Fischmeister, H.F., Schmauder, S., Sigl, L.S. (1988). Finite element modelling of crack propagation in WC-Co hard metals. Materials Science \& Engineering: A, vol. 105-106, p. 305-311, DOl:10.1016/0025-5416(88)90711-2.

[9] Hönle, S. (1998). Micromechanical Modelling of Deformation and Fracture of Graded WC-Co Hard Metals, MSc thesis, University of Stuttgart, Stuttgart. 
[10] Connolly, P., McHugh, P.E. (2002). Fracture modelling of WC-Co hard metals using crystal plasticity theory and the Gurson model. Fatigue \& Fracture of Engineering Materials \& Structures, vol. 22, no. 1, p. 77-86, D0l:10.1046/j.1460 2695.1999.00153.x.

[11] McHugh, P.E., Connolly, P.J. (2003). Micromechanical modelling of ductile crack growth in the binder phase of WCCo. Computational Materials Science, vol. 27, no. 4, p. 423436, D0I:10.1016/S0927-0256(03)00045-4.

[12] Kim, C.S. (2004). Microstructural-Mechanical Property Relationships in WC-Co Composites, MSc. thesis, Carnegie Mellon University, Pittsburgh.

[13] Kim, C.-S., Massa, T.R., Rohrer, G.S. (2006). Modeling the relationship between microstructural features and the strength of WC-Co composites. International Journal of Refractory Metals and Hard Materials, vol. 24, no. 1-2, p. 89100, D0I:10.1016/j.jijmhm.2005.04.011.

[14] Park, S. (2007). Development of a Microstructure-Level Finite Element Model for the Prediction of Tool Failure by Chipping in WC-Co Systems, MSc. thesis, University of Illinois at UrbanaChampaign, Urbana-Champaign.

[15] Sadowski, T., Nowicki, T. (2008). Numerical investigation of local mechanical properties of WC/Co composite. Computational Materials Science, vol. 43, no. 1, p. 235-241, DOI:10.1016/j.commatsci.2007.07.030.

[16] Carlsson, K. (2013). Modeling of Three Dimensional Microstructures Including Grain Boundary Mechanisms, MSc. thesis, Chalmers University of Technology, Gothenburg, p. 1020.

[17] Park, S., Kapoor, S.G., DeVor, R.E. (2006). Microstructure-level model for the prediction of tool failure in WC-Co cutting tool materials. Journal of Manufacturing Science and Engineering, vol. 128, no. 3, p. 739-748, Dol:10.1115/1.2194233.

[18] Park, S., Kapoor, S.G., DeVor, R.E. (2007). Microstructurelevel model for the prediction of tool failure in coated WC-Co cutting tool materials during intermittent cutting. Journal of Manufacturing Science and Engineering, vol. 129, no. 5, p. 893-901, Dol:10.1115/1.2738507.
[19] GB/T-6394:2002. Metal-Methods for Estimating the Average Grain Size. Standardization Committee of China, Beijing. (in Chinese)

[20] Zhu, J.-F., Zhang, L., Xu, T., Zhang, Z.-J., Liu, X.-Z., Wang, Z. (2015). Quantificational characterization of microstructural parameters of cemented carbides based on Image J software. Materials Science and Engineering of Powder Metallurgy, vol. 20, no. 1, p. 26-31. (in Chinese)

[21] Abaqus Analysis User's Manual (2011). Defining the Constitutive Response of Cohesive Elements using a Traction-Separation Description, vol. 4, sec. 31.5.6. SIMULIA, Providence.

[22] Gren, M. (2013). Molecular Dynamics Simulations of Grain Boundaries in Cemented Carbides, MSc. thesis, Chalmers University of Technology,Gothenburg.

[23] Tomar, V. (2008). Analyses of the role of the second phase SiC particles in microstructure dependent fracture resistance variation of SiC-Si3N4 nanocomposites. Modelling and Simulation in Materials Science and Engineering, vol. 16, no. 3, p. 1-17, DOl:10.1088/0965-0393/16/3/035001.

[24] Xu, X.-P., Needleman, A. (1994). Numerical simulations of fast crack growth in brittle solids. Journal of the Mechanics and Physics of Solids, vol. 42, no. 9, p. 1397-1434, Dol:10.1016/0022-5096(94)90003-5.

[25] MatWeb (2011). Engineering Materials Database Business, from http://www. matweb.com/services/services.aspx, accessed on 2011-4-4.

[26] Jiao, S., Jenkins, M.L., Davidge, R.W. (1997). Interfacial fracture energy-mechanical behaviour relationship in Al203/ $\mathrm{SiC}$ and Al203/TiN nanocomposites. Acta Materialia, vol. 45, no. 1, p. 149-156, D0l:10.1016/S1359-6454(96)00168-1.

[27] de Boer, F.R., Boom, R., Mattens, W.C.M., Miedema, A.R., Niessen, A.K. (1989). Cohesion in Metals. North Holland, Amsterdam.

[28] Griffith, A.A. (1921). The phenomena of rupture and flow in solids. Philosophical Transactions of the Royal Society A, vol. 221, no. 582-593, p. 163-198, Dol:10.1098/rsta.1921.0006. 